\title{
Production Efficiency Of the Construction Industry In Henan Province
}

\section{Based On DEA}

\author{
XU Dong-ming ${ }^{1, a}$ CUI Pei-lii, ${ }^{1, b}$ YANG Kai-wen ${ }^{2, c}$ \\ (1.Civil Engineering School of Henan University of Science \& Technology Henan Luoyang \\ 471023
}

2.LYC BEARING CO.,LTD Quality management department of engineering department Henan Luoyang 471309)

${ }^{1}$ School of Civil Engineering, Henan University of Science \& Technology, 263 Kaiyuan Avenue, Luoyang, Henan, China

a289533282@qq.com, ${ }^{\text {s }}$ suidom@163.com

\begin{abstract}
Keywords: Construction;DEA model; Production efficiency
Abstract.This paper evaluated the productivity of the construction industry in Henan province from three aspects including total productive efficiency, pure technical efficiency and scale efficiency, $b$ $y$ using of the DEA model based on the construction of Henan province in 2000-2014 input and out put historical data, at the same time, it analyzed the reasons for input redundancy and output deficie ncy of construction industry in Henan province. It pointed out that currently the overall production e fficiency of construction industry in Henan province is high, and the optimization of the industry is more reasonable, and it also brought forward an opinion for the future development of the constructi on industry in Henan province.
\end{abstract}

\section{Introduction}

Construction industry as a pillar industry in national economy plays a great role in contribution of the gross national product, solving labor employment and boosting economic growth.According to statistics, the proportion of The added value of China's construction industry in GDP was 6. $86 \%$ in 2013; the number of people employed in construction industry account for 13 . $19 \%$ of the employed, ranked second only to the manufacturing. At the same time, it can drive the development of more than 50 relevant industries such as the building materials, metallurgy, chemical industry and transportation; moreover, it has a strong impetus to the whole national economy.It can be said that construction industry is the "barometer" of the national economic development.

Henan province is an important economic province, the transport hub and logistics center in our country, the development of the construction industry is also becoming more and more important.In recent years, the volume of construction industry and scale has been expanding unceasingly in Henan province, the total assets of the employees and the enterprises have maintained a rapid growth. The total output value of construction industry in Henan province reached 791.2 billion yuan, ranked eighth in the country in 2014. With the support of "The central plains economic zone planning" (2012-2020) and "Zhengzhou Airport Economic Experimental Zone of comprehensive development planning (2013-1025)" approved by the State Council officially, the construction industry in Henan Province has a good room for growth and opportunities to develop.In September 2014, the Department of housing and city construction in Henan Province issued thirteenth five-year-planning work; the construction industry development planning is one of the six planning.

The study of construction production efficiency is helpful to find the problems in the development of construction enterprises, and to find the direction to improve the efficiency of the production. Yanli Liu [1] calculated and analyzed the production efficiency of Subordinate provinces of Henan province and the straight tube city construction by using of the DEA analytical procedure, by the way, it also pointed out the shortage of investment and output of the construction 
industry.Wei Li [2], Zhongfu Li and others [3] studied and evaluated the construction efficiency of China's provinces and regions based on the DEA model, putted forward suggestions for the development of the construction industry to every province.Gongxiang $\mathrm{Li}$ [4] studied the production efficiency of China's construction industry with super efficiency DEA method, improving the shortcomings of the traditional DEA model.Zongzhi Duan [5] using DEA technology research for east of China area construction efficiency, analyzed the advantages and disadvantages of each province of its development.Lianfa Ruan [6] made the harmonious degree evaluation on the development of construction industry in Zhejiang province with the DEA method, and further expanded the scope of DEA modelYu Li [7] analyzed the efficiency of construction from two directions including province and provincial in Liaoning province using the DEA model, and gave advice and opinions for the development of construction industry.Many scholars described the application of DEA model in the production efficiency of construction industry from different angles, enriched and extended the DEA model in the construction efficiency evaluation of empirical analysis, for the construction industry to improve production efficiency and provide the basis for later scholars in study of DEA model to provide a reference. This paper Study the productivity of the construction industry in Henan province from the three aspects of total productive efficiency, pure technical efficiency and scale efficiency, and its use the DEA model on the basis of reference of existing research results, taking the construction industry input-output data of -2014 in Henan Province in 2000 as the research object.Through the analysis and comparison, it points out the existing problems of the current construction industry in the production efficiency in Henan province, and brings forward opinions for the construction of Henan province to improve production efficiency.

\section{DEA Model}

\section{Introduction Of DEA Model}

Data Envelopment Analysis (DEA) is a non parameter evaluation method proposed by Chames. W.W.Cooper and other scholars on the basis of relative efficiency in 1978. It is mainly used to analyze the efficiency of multi input system. this method uses the structure of the weights of the input and output data sets to construct an efficient boundary which covers all data points, this boundary is composed of all the optimal efficiency of data connection, The relative efficiency of each point is calculated by the distance from the boundary. The evaluation model of DEA method includes $C^{2} R$ model and $C^{2} G S^{2}$ model. The $C^{2} R$ model is used to evaluate the total production efficiency of each decision making unit. The $\mathrm{C}^{2} \mathrm{GS}^{2}$ model is used to evaluate the pure technical efficiency of each decision making unit. Among them, the scale efficiency = total production efficiency / pure technical efficiency. The effectiveness of pure technical efficiency explains to achieve maximum output in fixed investment amount; the validity of the scale explain the investment scale of output is optimal ( increase investment $\mathrm{K}$ times, the output can be a corresponding increase in $\mathrm{K}$ times)

Suppose there are $\mathrm{N}$ the same type DMU, For each DMU has $m$ type of input and $p$ type of output. $\mathrm{x}_{\mathrm{ij}}$ is the input of the jth DMU mass of the ith input, $\mathrm{y}_{\mathrm{rj}}$ is the output of the jth DMU mass of the rth input. $x_{i j}>0 、 y_{r i}>0(i=1,2, \ldots m, r=1,2, \ldots p, j=1,2, \ldots n) 。$ Model as follows

$$
\begin{aligned}
& \theta^{*}=\min \theta \\
& \sigma^{*}=\text { mino } \\
& \text { s.t. }\left\{\begin{array}{c}
\sum_{\mathrm{j}=1}^{\mathrm{n}} \lambda_{\mathrm{j}} \mathrm{X}_{\mathrm{j}}+\mathrm{S}^{-}=\theta \mathrm{X}_{0} \\
\sum_{\mathrm{j}=1}^{n} \lambda_{\mathrm{j}} \mathrm{Y}_{\mathrm{j}}-\mathrm{S}^{+}=\mathrm{Y}_{0} \\
\mathrm{~S}^{-} \geq 0, \mathrm{~S}^{+} \geq 0, \lambda_{\mathrm{j}} \geq 0 \\
\theta \text { unrestraint }
\end{array}\right. \\
& \text { s.t. }\left\{\begin{array}{c}
\sum_{\mathrm{j}=1}^{\mathrm{n}} \lambda_{\mathrm{j}} \mathrm{X}_{\mathrm{j}}+\mathrm{s}^{-}=\sigma \mathrm{X}_{0} \\
\sum_{\mathrm{j}=1}^{\mathrm{n}} \lambda_{\mathrm{j}} \mathrm{Y}_{\mathrm{j}}-\mathrm{s}^{+}=\mathrm{Y}_{0} \\
\sum_{\mathrm{j}=1}^{\mathrm{n}} \lambda_{\mathrm{j}}=1 \\
\mathrm{~s}^{-} \geq 0, \mathrm{~s}^{+} \geq 0, \lambda_{\mathrm{j}} \geq 0
\end{array}\right.
\end{aligned}
$$

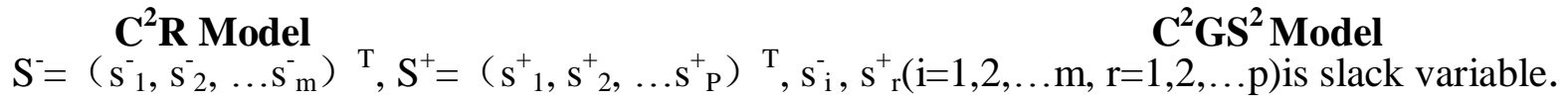




\section{Model Analysis}

There are optimal solutions that are $\lambda^{*}, \mathrm{~s}^{*}-, \mathrm{s}^{*}+$ and $\theta^{*}$ for equation $\mathrm{C}^{2} \mathrm{R}$ model. The following conclusions are got: 1 ) if $\theta^{*}=1$, and $\mathrm{s}^{*}=0, \mathrm{~s}^{*}+=0$, then DEA is effective (Total production efficiency) ;2) if $\theta^{*}<1$ and $\mathrm{s}^{*} \neq 0, \mathrm{~s}^{*}+\neq 0$, then DEA is invalid; 3 ) if $\theta^{*}<1$ and $\mathrm{s}_{-}=0, \mathrm{~s}^{*}+=0$, then the weak DEA is effective.

There are optimal solutions that are $\lambda^{*}, s^{*}, s^{*}+, \sigma^{*}$ for equation $\mathrm{C}^{2} \mathrm{GS}^{2}$ model, the equation reflects the pure technical efficiency. The following conclusions are got: 1) if $\sigma^{*}=1$, then the weak DEA is effective (Pure technical efficiency); 2) if $\sigma^{*}=1$, and $\mathrm{s}_{-}^{*}=0, \mathrm{~s}^{*}+=0$, then the DEA is effective; 3) if $\sigma^{*}<1$, then the DEA is invalid. The results are analyzed by projection method under technical efficiency invalid to make the DMU output reaches DEA effective.

Effectiveness is that: 1) Any kind of output can not be increased in the current environment, unless reducing other types of output at the same time; 2) Any input can not be reduced to achieve the current output, unless increasing other types of input simultaneously. If a decision-making unit reached $100 \%$ efficiency, the decision unit is effective, that is, a effective DMU.

\section{Empirical Analysis}

\section{Data Sources \&Index Selection}

Construction investment efficiency index selection generally as capital,technology,humaninput, This article selects construction enterprise total assets, rate of technical equipment, workforce to reflect the above indicators. With the development of modern construction enterprise, Enterprise's organizational efficiency influence on production efficiency increasing, So this article use the number of enterprise to reflect the index of organizational efficiency. selects the construction industry output value and profit to reflect the index of output. The above data are from China statistical yearbook.

Model Solve \& Analysis

Combined with construction input and output data of henan province, develop a fresh DEA mode, Use of DEAP2.1 software to solve the construction efficiency of henan province:

Table 1 Construction input and output efficiency of henan province

\begin{tabular}{ccccl}
\hline Year & crste & vrste & scale & \\
\hline 2000 & 0.650 & 1.000 & 0.650 & irs \\
2001 & 0.671 & 1.000 & 0.671 & irs \\
2002 & 0.620 & 0.966 & 0.641 & irs \\
2003 & 0.628 & 1.000 & 0.628 & irs \\
2004 & 0.640 & 0.837 & 0.765 & irs \\
2005 & 0.747 & 0.858 & 0.871 & irs \\
2006 & 0.879 & 0.957 & 0.918 & irs \\
2007 & 0.940 & 0.987 & 0.953 & irs \\
2008 & 0.966 & 0.991 & 0.974 & irs \\
2009 & 0.978 & 0.988 & 0.989 & irs \\
2010 & 1.000 & 1.000 & 1.000 & - \\
2011 & 1.000 & 1.000 & 1.000 & - \\
2012 & 1.000 & 1.000 & 1.000 & - \\
2013 & 1.000 & 1.000 & 1.000 & - \\
2014 & 1.000 & 1.000 & 1.000 & - \\
mean & 0.848 & 0.972 & 0871 & \\
\hline
\end{tabular}

\section{The Quondam Qroductivity}

DEA effective date for the 2010-2014, In recent years, with the high-speed development of construction industry in henan province, Construction enterprise of input and output of the allocation of resources is relatively reasonable. Weak DEA effective date for the 2000, 2001, 2003, Construction of pure technical efficiency and effective during this period. In the stage of increasing scale efficiency. DEA is invalid for 2002, 2004-2009, Both in pure technical efficiency and scale efficiency in DEA is invalid during this period. On the whole ,Henan province construction productivity growth gradually tends to DEA efficient over time. To illustrate the development 
towards the direction of the positive construction of henan province.

\section{The Analyzed Of Input Redundancy And Output Deficiency}

Through the table 2 shows that: In 2002 -2009 years of redundant input and inadequate output exis. Capital input redundancy disappear after 2005, It shows that after 2005 investment in the capital of henan province construction enterprise gradually optimized.For a long time, Technical input redundancy always keep a larger proportion shows that technology did not bring higher contribution for output. The enterprise organization efficiency and human input redundancy increases gradually after 2005, Since 2005, countries increased the investment in fixed assets and real estate market overheating, to promote the development of construction high speed. A lot of resources and enterprise into the construction industry, Construction become a resource intensive. The overheating of the real estate market lead to the improvement of the utilization rate of capital, The capital input redundancy in the later disappearance of anastomosis.

Table 2 Insufficient output and input redundanc

\begin{tabular}{rrrrrrr}
\hline year & $\mathrm{s}_{1}^{+}$ & \multicolumn{1}{c}{$\mathrm{s}_{2}^{+}$} & \multicolumn{1}{c}{$\mathrm{s}_{1}^{-}$} & \multicolumn{1}{c}{$\mathrm{s}_{2}^{-}$} & \multicolumn{1}{c}{$\mathrm{s}_{3}^{-}$} & \multicolumn{1}{c}{$\mathrm{s}_{4}^{-}$} \\
\hline 2002 & 0.000 & 1.899 & 44.773 & 1213.907 & 3.757 & 0.000 \\
2003 & 0.000 & 4.172 & 87.331 & 3328.120 & 5.585 & 0.000 \\
2004 & 0.000 & 3.218 & 2.363 & 4062.091 & 0.000 & 0.000 \\
2005 & 0.000 & 5.377 & 0.000 & 1929.143 & 0.200 & 42.387 \\
2006 & 0.000 & 12.014 & 0.000 & 2986.277 & 10.437 & 46.018 \\
2007 & 0.000 & 16.028 & 0.000 & 1973.589 & 25.427 & 40.517 \\
2008 & 0.000 & 6.904 & 0.000 & 1822.686 & 21.603 & 438.305 \\
2009 & 0.000 & 11.446 & 0.000 & 593.754 & 17.549 & 225.223 \\
\hline
\end{tabular}

\section{Conclusion}

The article evaluated construction industry input-output efficiency and analyzed input redundancy and output deficiency of Henan province in 2000-2014 based on the DEA model. Henan province construction overall production efficiency gradually increase by constantly adjust the allocation of resources, optimizing the industrial structure in recent years after experiencing rapid development stage, degree of resource utilization is in a healthy and reasonable level.

Henan province construction should continue to pay attention to scientific and technological innovation,increase investment in new technology,applicate advanced management measures, change the traditional extensive development pattern, improve the quality of the practitioners, not blindly increase the resources, pay attention to optimize the allocation of resources and energy efficiency, take the road to sustainable and healthy development.

\section{References}

[1]YanLi Liu:Input-output analysis of construction industry in Henan province.Henan University of Urban Construction, 2013 (11): 32-36

[2]Wei Li,GuangHui Li, YueJuan Li andPeiYun Jia : various provinces construction production efficiency evaluation of empirical research Based on DEA .Science and Technology Progress And Policy,2009 (21): 153-155

[3]ZhongFu Li,HuiMo Wang : A Study on Production Efficiency of Chinese Construction Industry Based On DEA.Journal of Systems \& Management, 2011 (3): 307-312

[4]GongXiang Li, YiLin Yin : On Productivity Evaluation of China's Construction Industry On the Basis of the Supper-efficient DEA Model.Journal Of Beijing Institute Of Technology(Social 
Sciences Edition), 2009 (4): 36-40

[5]ZongZhi Duan :Production Efficiency Of the Construction Industry in East China Based on DEA.Chinese Journal Of Management, 2011 (7): 1102-1105

[6]LianFa Ruan, YueWei Zhang :Research on Zhejiang Construction Industry Development Based on DEA Analysis.Technoeconomics\&Management Research， 2009 (6): 22-24

[7] Yu Li,JinYao Li,MengNan Li :Production Efficiency Of the Construction Industry in Liaoning Province Based on DEA.Journal of Dalian Jiaotong University, 2014 (6): 97-100

[8]National Bureau of Statistics of the people's Republic of China.China Statistical Yearbook. Beijing: China Statistics Press,2015 